Technical Note

\title{
Spatio-Temporal Metocean Measurements for Offshore Wind Power
}

Lucy Wyatt *

School of Mathematics and Statistics, University of Sheffield, Sheffield, UK and Seaview Sensing Ltd;

E-Mail: l.wyatt@sheffield.ac.uk

* Correspondence: Lucy Wyatt; E-Mail: I.wyatt@sheffield.ac.uk

Academic Editor: Andrés Elías Feijóo Lorenzo

Special Issue: $\underline{\text { Offshore Wind Farms }}$

Journal of Energy and Power Technology

2021, volume 3 , issue 1

doi:10.21926/jept.2101005
Received: November 24, 2020

Accepted: January 19, 2021

Published: January 22, 2021

\begin{abstract}
This paper presents the case for the use of HF radar to provide wave, current and wind measurements and maps during the surveying, resource and impact assessment, construction, maintenance and performance assessment phases of an offshore fixed or floating wind farm or other marine renewable project. The data presented are from the Celtic Sea which is currently the focus of a lot of offshore wind interest. The data are from a dual radar system deployed at the Wave Hub site off the Cornwall coast since 2011, a single radar system in North Devon reactivated in 2017, and data from 2005 when the North Devon radar was operated as a dual radar with a second site in South Wales. The accuracy of the wave and wind data is discussed and examples of the sort of data that could be available are presented.
\end{abstract}

\section{Keywords}

HF radar; metocean measurements; offshore wind; resource assessment; monitoring

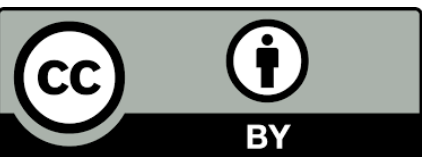

(C) 2021 by the author. This is an open access article distributed under the conditions of the Creative Commons by Attribution License, which permits unrestricted use, distribution, and reproduction in any medium or format, provided the original work is correctly cited. 


\section{Introduction}

The UK is the world's largest generator of electricity from offshore wind. Surveying, resource and impact assessment, construction, maintenance and performance assessment all require information about winds, waves and currents in the region of interest. For example:

- "Resource and metocean assessment is carried out to provide atmospheric and oceanographic datasets to inform the engineering design of a wind farm, the potential future energy production, and to fully describe the likely operating conditions at the proposed wind farm location" [1].

- $\quad$ "better weather monitoring together with the availability of vessels with lower metocean limitations can help to reduce weather downtime" [2].

- The cost benefit will also differ between concepts, largely due to the met-ocean limitations and conditions in which the structures can be towed back to shore and then back to site"[2].

Short-term forecasting is needed as discussed in [3] from which the following are extracted.

- $\quad$ "An accurate short-term prediction (few hours - one day) of the power output is needed both to bid at energy auctions (where energy companies sell power) and to plan maintenance of the energy harvesters. The power output is due to a combination of the weather forecast and the control system of the farm. It requires advanced integrated modelling of the whole weather-farm system."

- $\quad$ "Accurate forecasting of site met conditions and consequent plans and decisions about work at site are typically based on a small number of in site devices coupled with algorithms to extrapolate across the site. With a reduction in cost, many more sensors could be deployed leading to much better information about the conditions at site (e.g. wind speed, wind direction, wave height, wave period etc.)."

Accurate forecasts require accurate measurements and, as emphasised in the above quote, accurate forecasts in coastal seas require measurements that reflect the spatial and temporal variability of these seas due to local topography, orography and bathymetry. The spatial picture is important for optimal siting of devices, for assessing safe passage from coast to site and also for impact assessment which isn't necessarily limited to the immediate vicinity of wind farms. This can be achieved using multiple in situ devices or using land- or satellite- based remote sensing. This paper is aimed at presenting the advantages of land-based remote sensing using HF radar systems, see section 3 , but first in section 2 the other options are briefly reviewed.

\section{Technology Options}

\subsection{Wind}

The wind is of course the primary resource for offshore wind power and accurate measurements are required to assess the resource and monitor performance. Wind measurement for offshore wind applications have traditionally been made using tower based anemometers. In recent years these are being replaced by lidars on platforms or metocean buoys which have been shown to provide measurements of similar accuracy and are much cheaper [1]. These devices can make measurements at the height of a proposed turbine and therefore provide reliable estimates of resource at that location. The Carbon Trust [4] requires a linear regression slope of 0.98-1.02 and $\mathrm{R}^{2}>0: 98$ for wind speed measured with LiDAR compared with mast data. 
Satellite scatterometer measurements are available to provide global and regional maps of wind climate and estimated wind power resource [5-7]. The accuracy requirements (compared with buoy measurements) for operational satellite scatterometer wind speeds are bias $<0.5 \mathrm{~m} / \mathrm{s}$ and standard deviation $<2 \mathrm{~m} / \mathrm{s}$ on a monthly basis [8]. The latest results [9] show biases of $0.2-0.3 \mathrm{~m} / \mathrm{s}$ and standard deviations of $1.2-2.2 \mathrm{~m} / \mathrm{s}$. These measurements are not at mast height, modelling of the vertical profile is required to extrapolate; are not as accurate as LIDAR; are not available continuously at a specific location but do provide a spatial picture of wind fields when the satellite is crossing the region of interest.

\subsection{Wave}

In the context of offshore wind, wave measurements are needed to inform the location and design of structures, both platform-based and floating, and cables and to ensure safe conditions for installation, maintenance and decommissioning operations. Wave buoys, in particular the Datawell directional waverider, are considered to be the industry standard against which all other measurements are assessed. While individual buoys are relatively cheap [1], they require suitable weather windows and ship costs to deploy and maintain and can lose their moorings especially in busy shipping and fishing areas. Multiple buoys to provide more detailed information soon increases the cost of course.

Microwave radar systems, of navigation radar [10] or altimeter [11] type, mounted on platforms are also an option for wave measurement. These can measure wave parameters such as significant waveheight, peak period and direction, as well as the directional spectrum. Like buoys these are point measurements and multiple systems would be required to get a more complete spatial picture.

Waves can be measured from satellite using altimeters [12] and synthetic aperture radars (SAR) [13] (note that these papers also refer to wind speed measurements). Altimeters only measure limited non-directional wave parameters, significant waveheight and period; SARs measure the directional spectrum of long waves. Coverage from both are of course limited by their orbits.

\subsection{Current}

Current measurements need to be accounted for similar reasons to those referred to in section 2.2 and also because wind farms may have an impact on the local dynamics which can have environmental impacts in the immediate vicinity and downstream. Standard systems for current measurement are current meters mounted below buoys and ADCPs (acoustic doppler current meters) either mounted on buoys or at the sea bed. Microwave radars can also provide local surface current measurements [10].

Satellites can measure large scale geostrophic currents using altimeters [14]. More detailed measurements of currents in coastal areas are being developed using interferometric SAR techniques [15] but these are not yet operational products.

\subsection{The Alternative}

$\mathrm{HF}$ radar located on the coast is the only technology that can provide continuous monitoring of waves, winds and currents in coastal waters on a spatial scale (from the coast to over $120 \mathrm{~km}$ offshore) suitable for offshore wind. HF radars are now routinely used for surface current 
measurement in many parts of the globe with networks around most of the coast of the USA and other countries aiming to achieve this [16-19]. In the next section this technology is reviewed and examples of available data are presented.

\section{HF radar}

\subsection{Theory and Methods}

Metocean measurements are obtained from the radar signal scattered from ocean waves. The motion of the waves, i.e their intrinsic phase speed and any underlying current, impose a Doppler shift on the received signal and the amplitude of the signal is related to the energy in the wave field which in turn is linked to the local wind plus any swell systems. The Doppler shift can be measured very accurately from what is usually referred to as the first order return in the power spectrum of the received signal which is due to waves with half the radio wavelength propagating towards (producing a positive Doppler shift) and away from (negative) the radar. The current measurement is obtained from the frequency asymmetry of these two signals since, for example, a current propagating towards the radar will impose a positive Doppler shift in both cases [20]. The two waves generating the first order signals are normally driven by the local wind and their relative amplitudes, together with a wind wave directional model, allow wind direction to be measured [21-23].

Wave measurements are obtained from the so-called second-order part of the power spectrum following the work of Barrick [24, 25]. A number of methods have been developed to solve the Barrick equations. In this paper the method of Wyatt and colleagues [21, 26, 27], is used. This method obtains the ocean wave directional spectrum up to a maximum frequency which depends on radar operating frequency and includes both swell and wind waves unless the wind speed is very low. Wave parameters such as significant wave height, peak and mean period and direction are determined from the spectrum using standard methods. The method has been tested on hundreds of hours of data from many different sites in the UK, Europe, USA, Australia, Canada, Taiwan and on different radar systems establishing that where radar data quality is good, good quality wave measurements are obtained [28].

Wind speed is a more difficult parameter to extract from the HF radar signal. The first order peaks are generated by the local wind but the wind wave spectrum saturates as wind speed increases. The full directional spectrum is contributing to the signal amplitude so could include waves that are not generated by the local wind. A number of potential methods have been suggested which look for regions of the radar power spectrum that are more likely to be locally wind related [29-31], relate wind to the detided current [32] or which assume the impact of swell on the measured wave parameter (or the features from which they are derived) is small so relationships can be found using wave model [33] or neural network [34] methods. The Dexter and Theodorides method [33] is currently implemented in the Seaview Sensing Ltd (SV) software package from which wave, current and wind measurements are presented in Section 3.2. The wind speed results are not sufficiently robust and this aspect of the package is not normally promoted. Research into the use of machine learning methods is underway with encouraging early results (see Section 3.2.3). Another approach currently being investigated involves partitioning the directional spectrum into swell and wind sea fields [35] and applying the modeling approach to the wind-sea partition alone. 
Note that at least two radar systems are needed to make all of these measurements, unless other information from models or other measurements is available, in order to resolve direction and amplitude ambiguities inherent in the scattering process [28].

\subsection{Data and Validations}

\subsubsection{The Celtic Sea}

The Celtic Sea between Ireland and the south-west of Great Britain is one area around the UK being considered for offshore wind exploitation and in particular floating wind [36, 37]. The exploitation of wave and current power is also being considered in this region [37]. It is also an area where the original UK work on ground-based HF radar was carried out [38] and is currently the only site in the UK where there are HF radar installations: a Pisces radar [39] is located in North Devon and operated by Neptune Radar Ltd and two WERAs [40] are located in North Cornwall operated by the University of Plymouth (UoP) (see Figure 1). The Seaview Sensing software metocean measurement package is used with both these installations. The wave and wind direction measurements have been validated in a number of different deployments [22, 23, 41-45], as well as at these sites $[46,47]$. This paper will show results from the Celtic Sea.

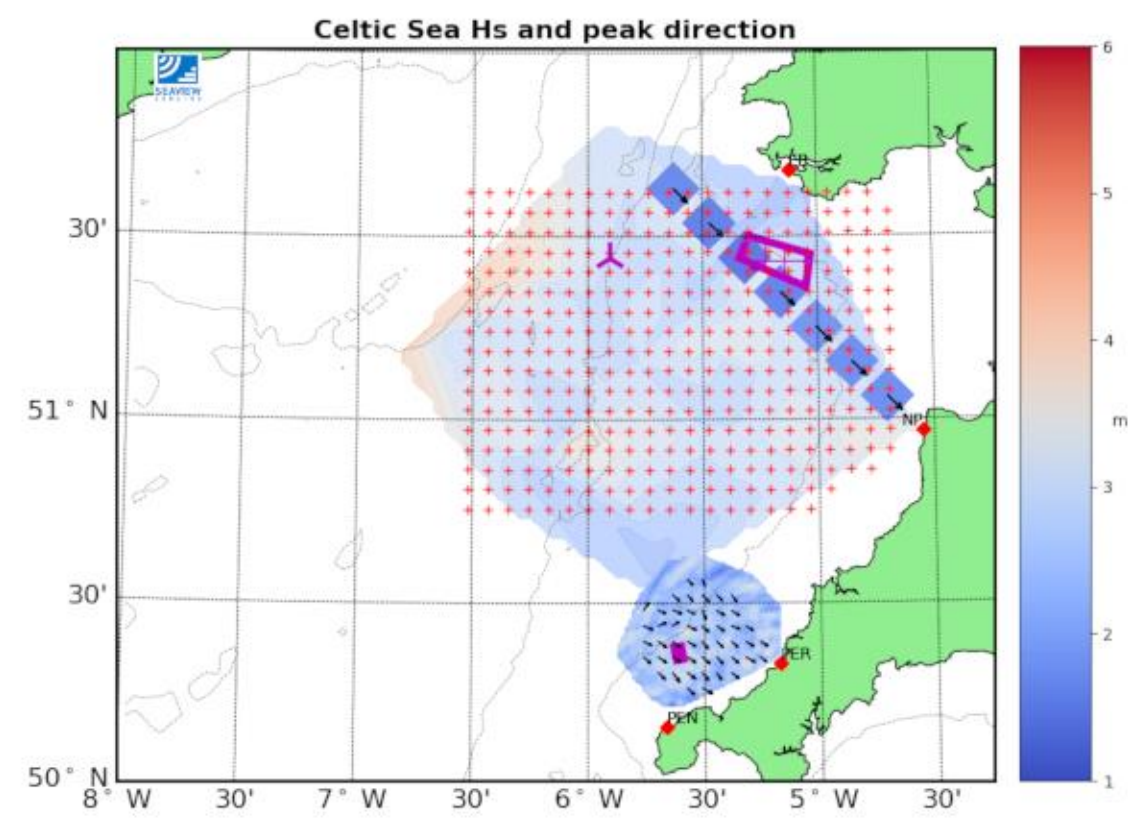

Figure 1 Map of the Celtic Sea showing radar coverage and offshore wind and wave power sites. Radar sites are shown with red diamonds. Sample measured wave maps are shown with the colour-coding scale on the right. + mark positions of a potential measurement grid for future work. Sites earmarked for offshore wind and/or wave power exploitation are shown with magenta outlines (Pembrokeshire and Cornwall Wave Hub) and the symbol $入$ (Erebus). See text for more details.

The measurements in Wyatt et al [46] were made using the North Devon Pisces together with a second Pisces which was located on the South Wales coast. The second site was removed after the operational trial was completed in 2005. From 2017, the Devon site was put back into operation to test a new version of Pisces capable of operating simultaneously on two different frequencies which 
would provide more robust measurements over a wider range of wave conditions and, it was hoped, would provide the additional information needed to resolve the ambiguities in single radar wave measurement. The results showed promise [39] but more work was needed before a full trial of the system and this work is ongoing. The aim is to install a second site for a thorough test of the new system. Such a test would also provide operational data using already proven methods.

The UoP radars were installed in 2011 with the aim of providing wave measurements to support the Wave Hub site being developed for wave power device testing [37]. This system has been operating continuously since that time, has been used for wave validations [47] over extensive periods, for testing new methods [48], and has recently begun supplying data to the EU HFR Node for inclusion in CMEMS-INSTAC.

A map of the radar sites in the Celtic Sea is shown in Figure 1. The UoP radar sites are at Pendeen (PEN) and Perranporth (PER). Pisces is located at Nabor Point (NP) and the S. Wales site used for the operational trial is shown with EB. A sample UoP radar waveheight/peak direction measurement is shown with directions sub-sampled for clarity. The wind was blowing towards the radar but there was also some swell from the west. The shaded region under the red grid shows a waveheight map from the Pisces operational trial using single radar data from both sites to show maximum coverage. A sample of the more recent single radar dual-frequency measurements for a case when winds were blowing towards the NP radar is shown. Measurements were made along a single radar beam. These are not at the same time as the UoP measurements. The red + mark positions of a potential grid for future testing of this system with just one radar at NP and possibly with a second radar in South Wales. Sites that have been earmarked for initial offshore wind and/or wave power exploitation are marked with magenta outlines and the symbol $入$.

\subsubsection{Validations}

Figure 2 shows a significant waveheight comparison for three months of the Pisces deployment. Unfortunately the buoy had lost its mooring in Dec 2004 and was not recovered and replaced until after the stormy period in early January. The radar storm waveheights are consistent with wave model data for this period. Figure 3 shows significant waveheight, energy period and peak period and direction measured with the UoP WERA system during a one month period in 2012.

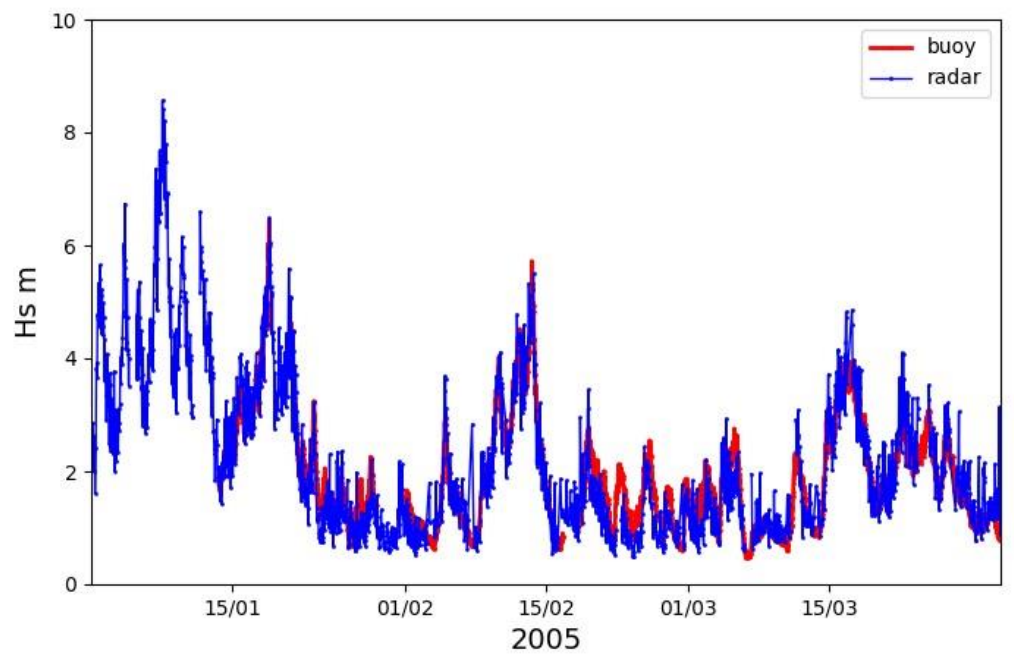

Figure 2 Pisces significant waveheight comparison between buoy (red) and radar (blue). 

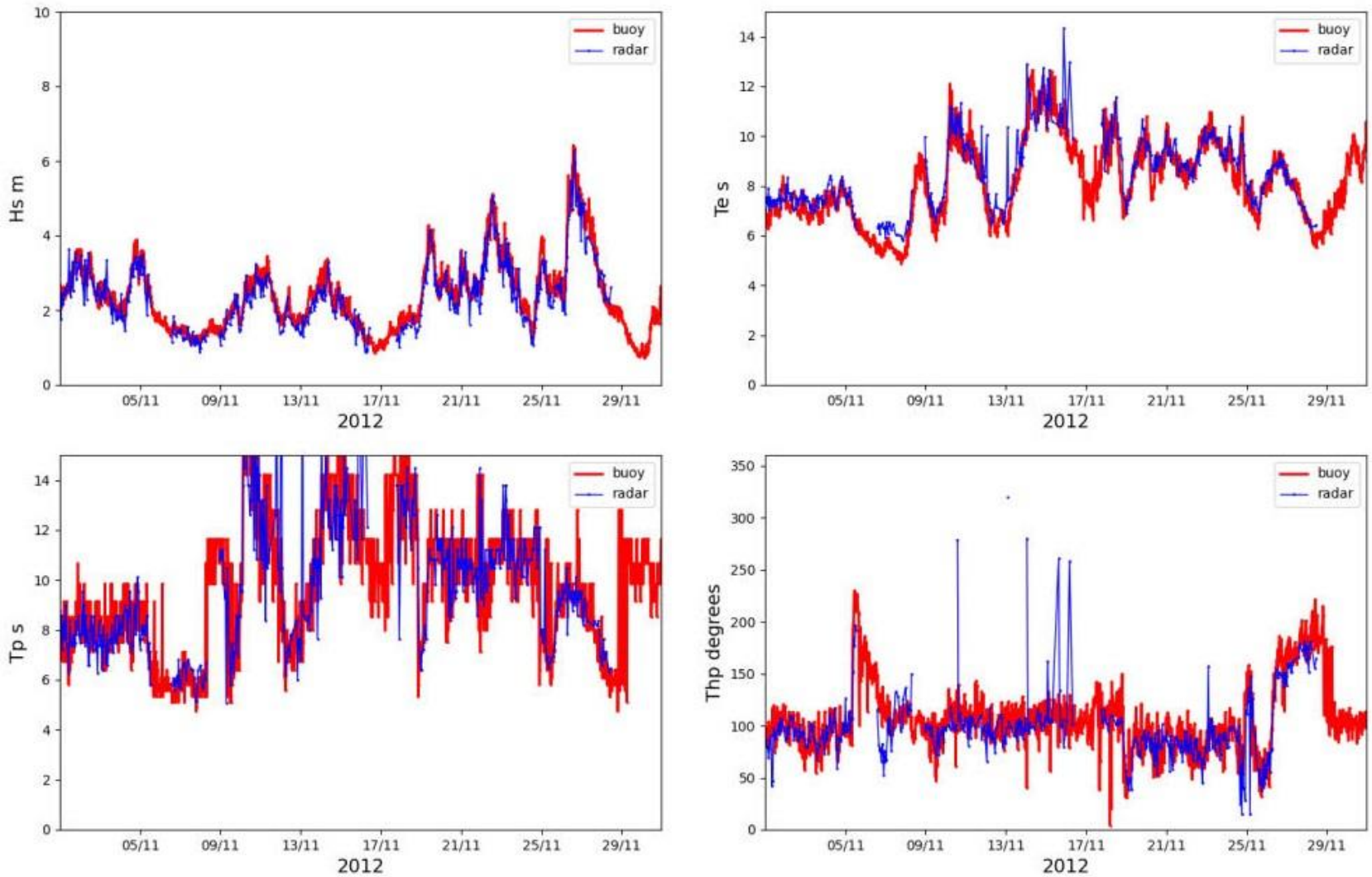

Figure 3 WERA wave parameter comparisons between buoy (red) and radar (blue).

Both data sets show good agreement. There are differences, usually in periods of low waveheights when other signals such as ships or sidelobe impacts [49] corrupt the sea signal. Peak period and direction have more variability with any measurement system (as can be seen in both buoy and radar data in Figure 3 ) because they do not involve any integration over frequency. The statistics of the UoP radar wave comparisons are presented in Table 1. These are similar to those presented in Lopez et al [47] where a longer data set of 8 months was used and validations were carried out at more than one location.

Table 1 Statistics of the UoP wave parameters. rms - root mean square difference; $\mathrm{SI}$ scatter index; cc- correlation coefficient, vc - vector correlation; diff - mean difference; $95 \% \mathrm{ci}$ is the $95 \%$ confidence interval for the mean difference; conc - is an inverse measure of the spread of the directional difference.

\begin{tabular}{llllllll}
\hline parameter & buoy mean/std & radar mean/std & bias & rms & SI & cc & N \\
\hline$H s, \mathrm{~m}$ & $2.59 / 0.87$ & $2.43 / 0.87$ & 0.15 & 0.37 & 0.14 & 0.93 & 488 \\
$T e, \mathrm{~s}$ & $8.25 / 1.55$ & $8.54 / 1.45$ & -0.29 & 0.73 & 0.09 & 0.9 & 477 \\
$T p, \mathrm{~s}$ & $9.8 / 2.56$ & $9.69 / 2.68$ & 0.1 & 1.79 & 0.18 & 0.77 & 477 \\
\hline & & & $\mathrm{Vc}$ & Diff & $95 \% \mathrm{ci}$ & conc & \\
\hline$T h m$ & $95.38 / 28.74$ & $93.61 / 29.78$ & 0.93 & 3.03 & 21.29 & 7.96 & 477 \\
$T h p$ & $99.98 / 29.84$ & $94.7 / 31.82$ & 0.92 & 6.19 & 25.26 & 6.83 & 477 \\
\hline
\end{tabular}


Note that there are more $\mathrm{Hs}(\mathrm{N})$ cases for comparison. The spectral parameters of period and direction are flagged and not included in the statistics if $\mathrm{kOHs}<0.32$ where $\mathrm{k} 0$ is the radar wavenumber [50]. A lower limit of 0.12 is used for significant waveheight. Very low values of $\mathrm{kOHs}$ are cases where the spectral peak is close to the first order Bragg peak frequency where the theoretical underpinning of the inversion process fails. There are more low waveheight cases in the Pisces measurements shown in Figure 2, many are close to the $\mathrm{kOHs}$ limits consequently the statistics are not quite as good for the spectral parameters (they are reported in [46, 50]). Pisces can operate at a number of different frequencies and during that trial these were optimised to minimise external interference: low frequencies in the day, higher at night. They can also be optimised to wave conditions, i.e. to keep $\mathrm{kOHs}$ high enough. The availability now of simultaneous operation on two frequencies will also help in this respect.

\subsubsection{Wind Speed and Direction}

It was noted in Section 3.1 that wind speed is not yet an operational parameter although an estimate is provided in the SV software package. SV has begun to investigate machine learning methods. The work is in its early stages and details of the methods being tested are not included here although we do show some preliminary and encouraging results. To develop an effective algorithm for wind speed we need wind measurements at the position of the radar measurements. To date this has not been available in the Celtic Sea although we have obtained wind data from a coastal station at Perranporth through the Channel Coastal Observatory [51] and this is being used for algorithm development.

We are currently working with only one month of UoP radar data and have established that this is not really enough to provide a sufficiently reliable model using the machine learning methods we have tested. However, we do obtain results that are much better than our wave model based approach. Figure 4 shows scatter plots of wind speed for the model generated by one of the methods we are testing using $90 \%$ of the data on the left and the prediction using the remaining $10 \%$ on the right. The correlation coefficients of over 0.9 in both cases, over wind speed ranges from 1 to over $20 \mathrm{~m} / \mathrm{s}$, are huge improvements on 0.46 which is obtained with the currently SVimplemented wave model method at this location due to the ubiquitous presence of swell often dominating the wave spectrum. It is worth noting that we have obtained an rms figure of $<1.5 \mathrm{~m} / \mathrm{s}$ (compared to about $2 \mathrm{~m} / \mathrm{s}$ here) for a different data set (not in the Celtic Sea) for which, although radar data quality was not as good, we do have some local wind speed data. We expect an $r m s$ of $<$ $1 \mathrm{~m} / \mathrm{s}$ to be achievable when we have completed this work. This will not reach the accuracy expected for lidar measurements, nor is the measurement location nominally at turbine height although a model could be used to scale it, but the data will provide a large-scale complementary spatial map of wind speed and direction. Figure 5 shows a scatter plot of wind direction for all the UoP data set colour-coded with radar-measured wind speed. Bearing in mind that the radar measurements are not at the same location as the anemometer which is at the coast, the agreement is good with largest direction differences at low wind speeds. The statistics for the wind vector comparisons are presented separately for the $90 \%$ model development data and the $10 \%$ test data. These are very encouraging results. 

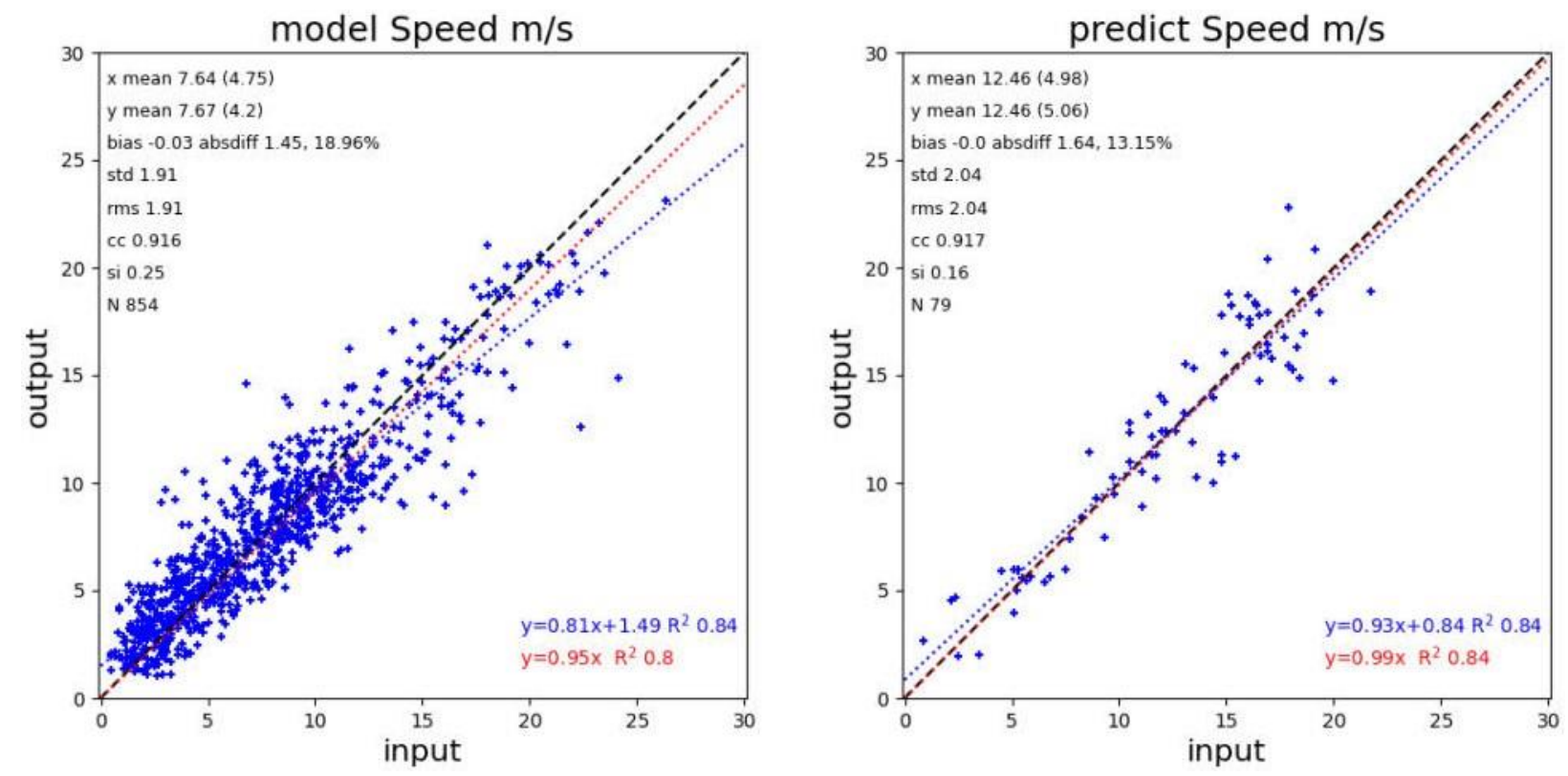

Figure 4 Wind speed scatter plots and statistics.

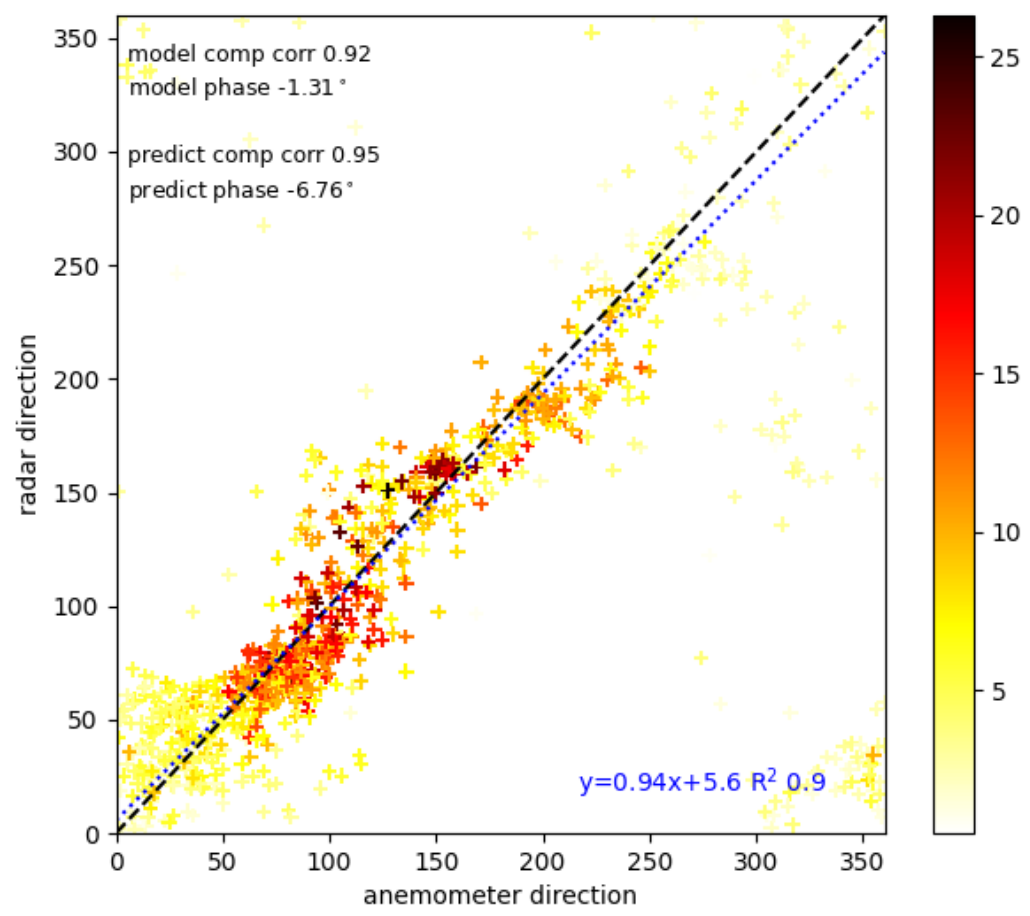

Figure 5 Direction scatter plot colour-coded by radar wind speed and vector statistics.

\subsubsection{Metocean Maps}

Having established the validity of the measurements the maps in Figure 6 show the spatial coverage potential of the radar systems in the Celtic Sea. The UoP measurements cover the Wave Hub site in the southern Celtic Sea; Pisces (with a second site in S Wales) could cover offshore wind sites in the northern Celtic Sea. The Pisces measurements are from the operational trial on 8/4/2005 @ 00:00 and the UoP measurements are from 24/11/2012 @22:05 so at different times, different 
metocean conditions and different phases of the tide although wind directions are roughly the same. The arrows are scaled according to the spatial resolution of the measurements and thus the scaling is different for the two radar systems. The details are not important. They have been combined here to illustrate coverage and spatial variability not to describe a particular event. The UoP wave, current and wind vectors and spectral data have been sub-sampled for clarity. For the same reason not all Pisces wave spectra are shown. Note that the wind speeds shown here are obtained with the standard SV method. The new method has not yet been extended to all locations. In the wave plot, the lighter shading, beyond the area containing arrows, shows the extent of single radar measurements.

(a)
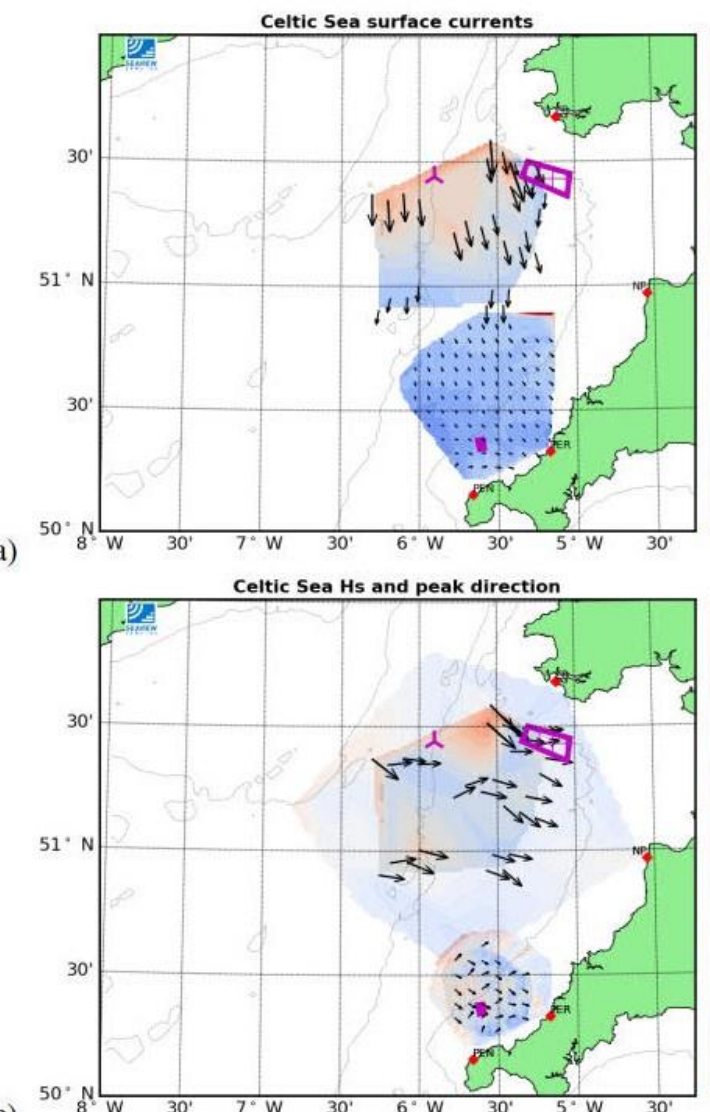

(b)
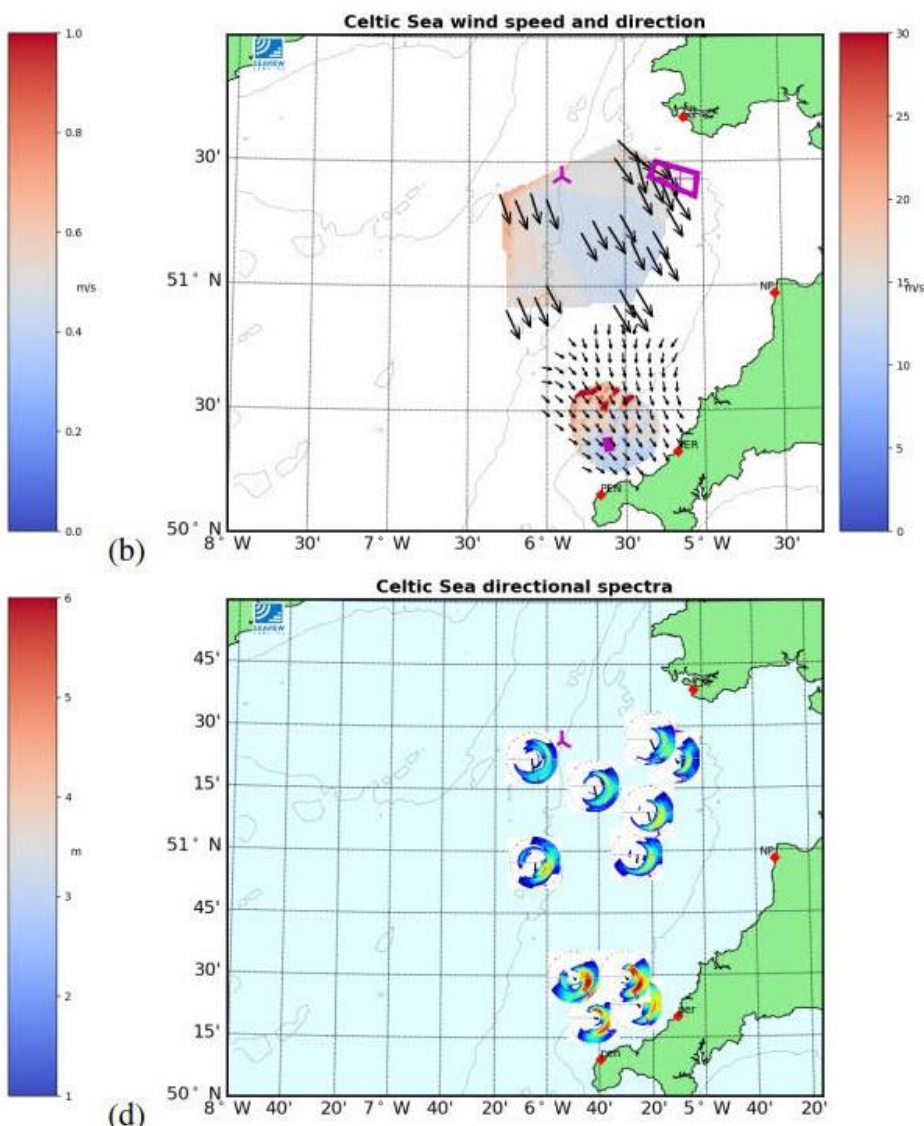

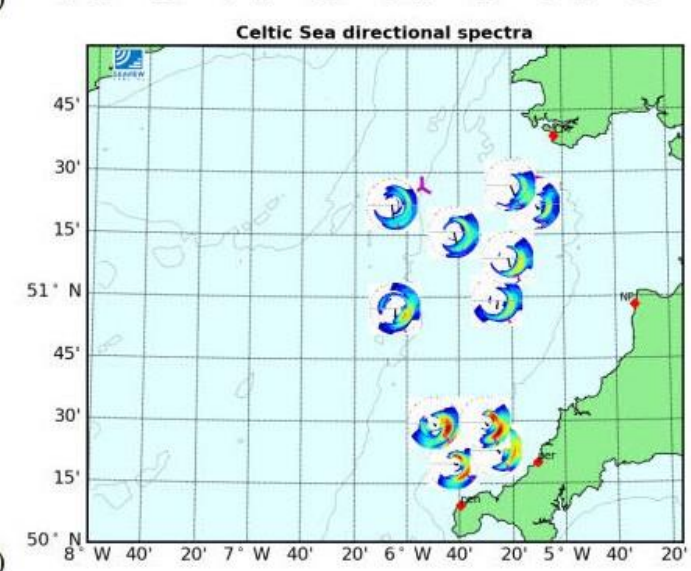

Figure 6 Maps of metocean measurements in the Celtic Sea: (a) surface current, (b) wind speed and direction, (c) waveheight and peak direction, (d) directional wave spectra, to illustrate potential coverage. Note that the measurements from the UoP and Pisces radars are at different times, different metocean conditions, different phases of the tide and with different spatial resolutions.

The Pisces operational trial was focussed on validating wave measurements at one location, approximately $60 \mathrm{~km}$ from both radar sites, and high spatial resolution was not required. Pisces is a more powerful radar than WERA and can measure waves, currents and winds to over $100 \mathrm{~km}$ as seen here. The UoP radar provides measurements over a more limited range but with high spatial resolution. It is normally that case that wave and wind speed measurements have a more limited range than current and wind direction, because signal to noise requirements are more strict, and this can be seen in the UoP plots. 


\section{Concluding Remarks}

We have demonstrated that wave measurements can be obtained with good accuracy and mapped over wide areas of the coastal ocean. New wind speed algorithms are being developed that show great promise. These will never be as accurate as lidar or mast data but they have the advantage of providing a spatial picture which is particularly important in coastal regions such as the Celtic Sea. Surface current measurement with HF radar is now well accepted and used in operational networks. We expect that the accuracy and coverage will be of value to the offshore wind sector.

HF radars will therefore provide very useful data for resource assessment, and the planning, operation and maintenance stages for wind farms. Once the wind farms are in operation the turbine motion produces identifiable signals in the radar return that do impact on wave and wind measurement accuracy in the immediate vicinity of the farms; less so on current measurement accuracy [52]. Removing these signals is an area of active and promising research. In the USA this is coordinated by the Wind Turbine Radar Interference Mitigation Working Group, a consortium of federal agencies together with interested research groups and radar operators both in the US and elsewhere including the UK where the issue was first identified. Success in this research effort will make it possible to measure metocean parameters accurately within wind farms.

At present there are just three radar systems on the Celtic Sea coast all on the north coast of the SW of England (PEN, PER and NP in Figure 6). The vision is to re-install a radar on the Welsh coast to provide coverage of the whole of the Eastern sector of the Celtic Sea combining information from all 4 radars. To obtain full coverage of the region, to meet the longer term aspirations of floating offshore wind developers radars will also be needed on the South-East coast of Ireland. Such a network of radars could also provide valuable data for many other applications such as shipping, fisheries, meteorological services and ground-truthing of satellite missions. The lifetime cost of a radar is equivalent to a small number of in-situ systems without the need for ship-time to deploy, maintain and recover. The cost of a radar will reduce over time if the offshore wind sector takes up this technology in the UK and the rest of the world.

\section{Acknowledgments}

The Pisces Celtic Sea data were provided by Neptune Radar and collected during a project funded by DEFRA and the MetOffice. The buoy data for this experiment have been provided by CEFAS. The UoP radar and buoy data were provided by Daniel Conley with financial support from the Natural Environment Research Council (Grant NE/J004219/1). The wind data were obtained from the Channel Coastal Observatory. Daniel Conley and Mike Moorhead (Neptune Radar Ltd) also provide helpful comments to improve the manuscript.

\section{Author Contributions}

The author did all work.

\section{Competing Interests}

The author has declared that no competing interests exist. 


\section{References}

1. BVG associates. Guide to an offshore wind farm. Glasgow: Offshore Renewable Energy Catapult; 2019. [cited date 2020 October 29]. Available from: https://www.thecrownestate.co.uk/media/2861/guide-to-offshore-wind-farm-2019.pdf.

2. Carbon Trust. Floating offshore wind market technology review. London: Carbon Trust; 2015. [cited date 2020 October 29]. Available from: https://www.carbontrust.com/resources/floating-offshore-wind-market-technology-review.

3. Offshore Wind Innovation Hub. O\&M and windfarm lifecycle. [cited date 2020 October 29]. Available from: https://offshorewindinnovationhub.com/category/operations-maintenance.

4. DNV GL, Frazer-Nash Consultancy, Multiversum Consulting, and Fraunhofer IWES. Carbon Trust Offshore Wind Accelerator Roadmap for the Commercial Acceptance of Floating LiDAR Technology. Version 2.0. 2018. [cited date 2020 October 29]. Available from: https://www.carbontrust.com/resources/roadmap-for-commercial-acceptance-of-floatinglidar.

5. Verhoef A, Vogelzang J, Verspeek J, Stoffelen A. Long-Term scatterometer wind climate data records. IEEE J Sel Top Appl Earth Obs Remote Sens. 2017; 10: 2186-2194.

6. Ahsbahs TT, Badger M, Volker P, Hansen KS, Hasager CB. Applications of satellite winds for the offshore wind farm site anholt. Wind Energy Sci. 2018; 3: 573-588.

7. Remmers T, Cawkwell F, Desmond C, Murphy J, Politi E. The potential of advanced scatterometer (ASCAT) $12.5 \mathrm{~km}$ coastal observations for offshore wind farm site selection in Irish Waters. Energies. 2019; 12: 206.

8. Meteo-France, Ifremer, MET Norway, DMI, KNMI. OSI SAF CDOP3 Product Requirement Document Version 1.4. 2018. [cited date 2020 October 29]. Available from: http://www.osisaf.org/sites/default/files/dynamic/public doc/osisaf_cdop3 gen_prd 1.4.pdf.

9. Meteo-France, Ifremer, MET Norway, DMI, KNMI. OSI SAF Half-Yearly Operations Report Version 1.4. 2020. [cited date 2020 October 29]. Available from: http://www.osisaf.org/sites/default/files/dynamic/public doc/osisaf cdop3 rp hyr20 h1 1 0.pdf.

10. Hessner KG, Nieto-Borge JC, Bell PS. Nautical radar measurements in Europe: Applications of WAMOS II as a sensor for sea state, current and bathymetry. In Remote Sensing of the European Seas. Berlin: Springer; 2008. pp. 435-446.

11. van der Vlugt $T$, van der Vlugt R. Comparison of directional WaveGuide Radar with Directional WaveRider buoy. Madrid: Environmental XPRT; 2014. [cite date 2020 October 30]. Available from: https://www.environmental-expert.com/articles/comparison-of-directional-waveguideradar-with-directionalwaverider-buoy-503676/full-article.

12. Ribal A, Young IR. 33 years of globally calibrated wave height and wind speed data based on altimeter observations. Sci Data. 2019; 6: 77.

13. Zhang B, Li X, Perrie W, He Y. Synergistic measurements of ocean winds and waves from SAR. J Geophys Res Oceans. 2015; 120: 6164-6184.

14. Dohan K, Maximenko N. Monitoring ocean currents with satellite sensors. Oceanography. 2010; 23: 94-103.

15. Martin AC, Gommenginger C. Towards wide-swath high-resolution mapping of total ocean surface current vectors from space: Airborne proof-of-concept and validation. Remote Sens Environ. 2017; 197: 58-71. 
16. Fujii S, Heron ML, Kim K, Lai JW, Lee SH, Wu X, et al. An overview of developments and applications of oceanographic radar networks in Asia and Oceania countries. Ocean Sci J. 2013; 48: 69-97.

17. Wyatt L. The IMOS ocean radar facility, ACORN. In Coastal Ocean Observing Systems. Cambridge, MA: Academic Press; 2015. pp.143-158.

18. Rubio A, Mader J, Corgnati L, Mantovani C, Griffa A, Novellino A, et al. HF radar activity in European coastal seas: Next steps toward a pan-European HF radar network. Front Mar Sci. 2017; 4: 8.

19. Roarty H, Cook T, Hazard L, George D, Harlan J, Cosoli S, et al. The global high frequency radar network. Front Mar Sci. 2019; 6: 164.

20. Wyatt LR, Mantovanelli A, Heron ML, Roughan M and Steinberg CR. Assessment of surface currents measured with High-Frequency Phased-Array Radars in two regions of complex circulation. IEEE J Ocean Eng. 2018; 43: 484-505.

21. Wyatt LR, Ledgard $L$, Anderson C. Maximum-likelihood estimation of the directional distribution of 0.53-Hz ocean waves. J Atmos Ocean Technol. 1997; 14: 591-603.

22. Wyatt LR. Shortwave direction and spreading measured with HF radar. J Atmos Ocean Technol. 2012; 29: 286-299.

23. Wyatt LR. A comparison of scatterometer and HF radar wind direction measurements. J Oper Oceanogr. 2018; 11: 54-63.

24. Barrick DE. The ocean waveheight nondirectional spectrum from inversion of the HF sea-echo Doppler spectrum. Remote Sens Environ. 1977; 6: 201-227.

25. Barrick D. Extraction of wave parameters from measured HF radar sea-echo Doppler spectra. Radio Sci. 1977; 12: 415-424.

26. Wyatt LR. Limits to the inversion of HF radar backscatter for ocean wave measurement. J Atmos Ocean Technol. 2000; 17: 1651-1666.

27. Green JJ, Wyatt LR. Row-action inversion of the Barrick-Weber equations. J Atmos Ocean Technol. 2006; 23: 501-510.

28. Wyatt L. Ocean wave measurement. In Ocean Remote Sensing Technologies: High Frequency, Marine and GNSS-Based Radar. To be published in 2021.

29. Gaffard C, Parent J. Remote sensing of wind speed at sea surface level using HF skywave echoes from decametric waves. Geophys Res Lett. 1990; 17: 615-618.

30. Shen W, Gurgel KW, Voulgaris G, Schlick T, Stammer D. Wind-speed inversion from HF radar first-order backscatter signal. Ocean Dyn. 2012; 62: 105-121.

31. Kirincich A. Remote sensing of the surface wind field over the coastal ocean via direct calibration of HF radar backscatter power. J Atmos Ocean Technol. 2016; 33: 1377-1392.

32. Seroka G, Kohut J, Palamara L, Glenn S, Roarty H, Bowers L, et al. Spatial evaluation of highresolution modeled offshore winds using estimated winds derived from a network of HF radars. 2013 OCEANS - San Diego. San Diego, CA: IEEE; 2013. pp. 1-5.

33. Dexter PE, Theodorides S. Surface wind speed extraction from HF sky-wave radar doppler spectra. Radio Sci. 1982; 17: 643-652.

34. Zeng $\mathrm{Y}$, Zhou $\mathrm{H}$, Roarty $\mathrm{H}$, Wen $\mathrm{B}$. Wind speed inversion in high frequency radar based on neural network. Int J Antennas Propa. 2016; 2016: 2706521.

35. Waters J, Wyatt L, Wolf J, Hines A. Data assimilation of partitioned HF radar wave data into wavewatch III. Ocean Model. 2013; 72: 17-31. 
36. Erebus. Wales: Blue Gem Wind Ltd. [cited date 2020 November 04]. Available from: https://www.bluegemwind.com/our-projects/erebus/.

37. Wave Hub Limited. Cornwall: Wave Hub. [cited date 2020 November 04]. Available from: https://www.wavehub.co.uk.

38. Wyatt LR, Venn J, Burrows G, Ponsford A, van Heteren J, Moorhead M. HF radar measurements of ocean wave parameters during NURWEC. IEEE J Ocean Eng. 1986; 11: 219-234.

39. Wyatt LR, Moorhead M, Fairley IA. Developments in metocean HF radar technology, applications and accuracy. Proceedings of the ASME 2019 38th International Conference on Ocean, Offshore and Arctic Engineering; 2019 June 9-14; Glasgow, Scotland, UK. New York: American Society of Mechanical Engineers.

40. Gurgel KW, Antonischki G, Essen HH, Schlick T. Wellen radar (WERA): A new ground-wave HF radar for ocean remote sensing. Coast Eng. 1999; 37: 219-234.

41. Wyatt LR, Thompson SP, Burton RR. Evaluation of high frequency radar wave measurement. Coast Eng. 1999; 37: 259-282.

42. Wyatt LR, Green JJ, Gurgel KW, Borge JN, Reichert K, Hessner K, et al. Validation and intercomparisons of wave measurements and models during the EuroROSE experiments. Coast Eng. 2003; 48: 1-28.

43. Wyatt LR, Graber H, Haus B. Factors affecting the accuracy of SHOWEX HF radar wave measurements. J Atmos Ocean Technol. 2005; 22: 847-859.

44. Wyatt L. Measuring the ocean wave directional spectrum 'First Five' with HF radar. Ocean Dyn. 2018; 69: 123-144.

45. James C, Collopy M, Wyatt L, Middleditch A. Suitability of the southern Australia integrated marine observing system's (SA-IMOS) HF-radar for operational forecasting. J Oper Oceanogr. 2019; 12: 73-85.

46. Wyatt LR, Green JJ, Middleditch A, Moorhead MD, Howarth J, Holt M, et al. Operational wave, current and wind measurements with the Pisces HF radar. IEEE J Ocean Eng. 2006; 31: 819-834.

47. Lopez G, Conley DC. Comparison of HF radar fields of directional wave spectra against in situ measurements at multiple locations. J Mar Sci Eng. 2019; 7: 271.

48. Hardman R, Wyatt L. Inversion of HF radar Doppler spectra using a neural network. J Mar Sci Eng. 2019; 7: 255.

49. Wyatt LR, Liakhovetski G, Graber H, Haus B. Factors affecting the accuracy of SHOWEX HF radar wave measurements. J Atmos Ocean Technol. 2005; 22: 844-856.

50. Wyatt LR, Green JJ, Middleditch A. HF radar data quality requirements for wave measurement. Coast Eng. 2011; 58: 327-336.

51. Regional Coastal Monitoring Programmes. Perraporth. Southampton: National Network of Regional Coastal Monitoring Programmes of England. [cited date 2020 November 06]. Available from: https://www.channelcoast.org/realtimedata/?chart=76\&tab=qc\&disp_option=.

52. Robinson A, Wyatt L, Howarth M. HF Radar data availability and measurement accuracy in Liverpool Bay before and after the construction of Rhyl-Flats wind farm. J Oper Oceanogr. 2013; 6: 1-12. 
JEPT 2021; 3(1), doi:10.21926/jept.2101005

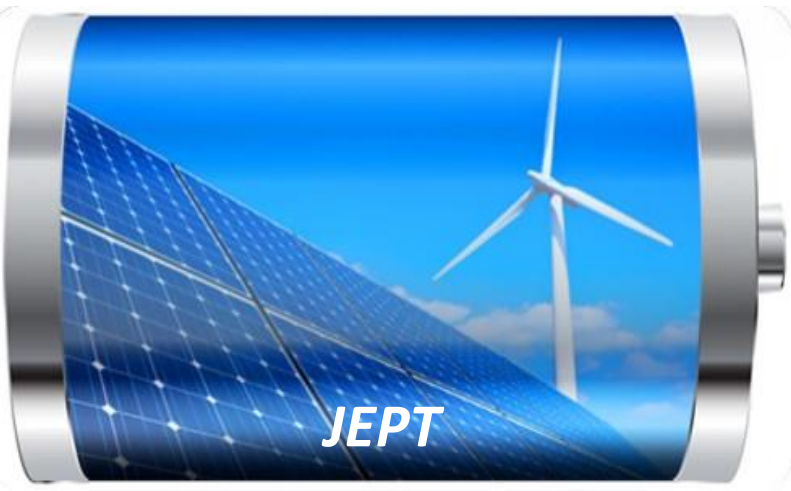

Enjoy JEPT by:

1. Submitting a manuscript

2. Joining in volunteer reviewer bank

3. Joining Editorial Board

4. Guest editing a special issue

For more details, please visit:

http://www.lidsen.com/journal/jept 